\title{
Subtraction-Like Effect in an Ant Faced with Numbers of Elements Including a Crossed One
}

\author{
Marie-Claire Cammaerts ${ }^{1} \&$ Roger Cammaerts ${ }^{2}$ \\ ${ }^{1}$ Retired from the Biology of Organisms Department, University of Brussels, Belgium \\ ${ }^{2}$ Retired from the Natural and Agricultural Environmental Studies Department (DEMNA) of the Walloon \\ Region, Belgium \\ Correspondence: Marie-Claire Cammaerts, Independent Researcher, 27, Square du Castel Fleuri, 1170 Bruxelles, \\ Belgium. Tel: 32-2-673-4969. E-mail: mccammaerts@gmail.com
}

Received: July 16, 2019

Accepted: August 8, 2019

Online Published: August 28, 2019

doi:10.5539/ijb.v11n4p51

URL: https://doi.org/10.5539/ijb.v11n4p51

\begin{abstract}
When trained to a number of colored elements of which one was crossed, tested Myrmica sabuleti worker ants reacted essentially to that number of elements excluding the crossed one. They thus apparently subtracted the crossed element, moreover doing so better for fewer numbers of elements. When trained in the same way but tested in front of a number of uncrossed elements equal to the total number of crossed and uncrossed elements seen during training, and at the same time, to the same number of elements without the crossed one as well as to the crossed element only, the ants again reacted essentially to the number of elements minus the crossed one. Again, they did so better for smaller numbers. The ants reacted thus to the visual cue they best saw during training. They also somewhat reacted to the isolated crossed element and better when trained to lower numbers of elements. When trained to a number of uncrossed colored elements and at the same time, to a cue showing the same number of elements, but one crossed and the others uncolored, the tested ants reacted more to the initial total number of colored elements than to the same total number of colored elements minus the crossed one. This showed again that the ants did not really subtract, but reacted to what they the most distinctly saw during training. They also again better reacted in presence of fewer elements.
\end{abstract}

Keywords: Conditioning, Counting, Myrmica Sabuleti, Subitizing, Visual Perception

\section{Introduction}

Ants can distinguish different numbers of elements, add numbers of elements when concretely seeing the addition (but not when consecutively seeing the elements), have a concrete notion of zero using their visual as well as their olfactory perception, locate the zero at its due place i.e. at the beginning of an increasing series of numbers and at the end of an decreasing series of numbers (respective references: Cammaerts, 2008; Cammaerts \& Cammaerts, 2019 C, D, A, B, submitted). It remained to see if ants could make subtractions, for instance subtract one element from a number of elements higher than one.

Research made on animals' numerosity abilities generally deals with their ability in distinguishing numbers, but seldom with their ability in adding numbers of elements, as well as with the notion of zero. Research also rarely deals with the animals' capability in subtracting such numbers. Indeed, it has been shown that spiders can retain (count) their captured preys but no attempt was made for evaluating their ability in adding or subtracting numbers of prey (Rodriguez, Bruceno, Briceno-Aguilar, \& Höbel, 2015). A recent work has shown that bees can learn to add and to subtract. These insects were successfully trained to add one element when the presented elements were blue and to subtract one element when they were yellow (Howard, Avarguès-Weber, Garcia, Greentree, \& Dyer, 2019). No work could be found on the problem of the subtracting ability in ants. Regarding the vertebrates, fishes have been shown to be able to count, or at least to estimate, different amounts (Agrillo, Dadda, Serena, \& Bisazza, 2008); no research on their potential ability in adding or subtracting amounts was made. Frogs were also shown to be able to count perceived sounds (Rose, 2018); no experimental examination was made as for their potential capability in adding and subtracting. Parrots can add numbers of elements (Pepperberg, 2006, 2012). Pigeons appear to be able to do subtractions, by comparing a constant number with that remaining after a subtraction (Brannon, Wusthoff, Gallistel, \& Gibbon, 2001). Young chicks can make consecutive additions and subtractions (Rugani, Fontanari, Simoni, Regolin, \& Vallortigara, 2009). Rats can evaluate quantities (Cox \& Montrose, 2016), 
but until now, there is no information about their adding and subtracting capability. Many works have been done on monkeys. One of them demonstrates their ability in adding elements (Boysen \& Berntson, 1989), and another one revealed their subtracting capability (Sulkowski \& Hauser, 2001). More information, beyond the sensu stricto topic of the present work, is given in the discussion section.

We here aimed to fill a gap about ants' cognition and numerosity abilities by looking if they could subtract numbers of elements. Firstly, we concretely trained the ants by presenting them a stand bearing a number of elements including a crossed one expected to be subtracted. We then tested these ants faced with the initial total number of elements, uncrossed and crossed, and with the number of uncrossed elements. Secondly, we trained identically the ants, but tested them faced with the total number of crossed and uncrossed elements, the number of uncrossed elements, and in addition the crossed element alone. Thirdly, we trained the ants to the same kind of expected subtraction but presenting it otherwise. The ants were faced at the same time with, separately, the initial number of colored elements, and the crossed element expected to be subtracted presented together with the complementary number of elements, the latter being this time not colored, but empty. We tested these ants faced with the initial total number of colored elements and with the same number of colored elements minus one.

\section{Material and Methods}

\subsection{Collection and Maintenance of Ants}

The experiments were conducted on eight colonies of Myrmica sabuleti Meinert 1861 (labeled A to H) collected in summer 2018 in two abandoned quarries, one located in the Aise valley (Ardenne, Belgium) and the other at Marchin (Condroz, Belgium). Each colony, containing about 500 workers, a queen and brood, was maintained in the laboratory in two to three glass tubes half filled with water, a cotton plug separating the ants from the water. The tubes of each colony were placed in a tray $(34 \mathrm{~cm} \times 23 \mathrm{~cm} \times 4 \mathrm{~cm})$ which served as foraging area and in which pieces of Tenebrio molitor larvae (Linnaeus, 1758) were deposited three times per week, and cotton plugged tubes filled with sugar water were permanently set. The ambient temperature was $c a 20^{\circ} \mathrm{C}$, the humidity $80 \%$, the lighting 330lux while working on ants, and the electromagnetism $2 \mu \mathrm{Wm}^{2}$, optimum environmental conditions for the species.

\subsection{Cues Presented to the Ants}

These cues were stands on which a given number of blue circles was tied (Figure 1, 3, 5). Each stand $(2.5 \mathrm{~cm} \times$ $2.5 \mathrm{~cm}$ ) was made of strong white paper (Steinbach $\AA$ ) and maintained vertically thanks to its duly folded horizontal base the surface of which equaled $2 \times(1.25 \mathrm{~cm} \times 0.5 \mathrm{~cm})$ (Figures 1, 3, 5, upper part). Different numbers of blue circles $($ diameter $=0.4 \mathrm{~cm})$ were drawn using Power Point $(\AA$ software, and printed, each one, in a $1.6 \mathrm{~cm} \times 1.6 \mathrm{~cm}$ square which was cut and finally tied to the front face of a stand. The number of stands presented to the ants differed according to the experiment. The numbers and the appearance of the blue circles tied to each stand differed according to the experiment and to the colonies used. For instance, during experiment I, one of the circles was crossed by a black segment during training (Figure 1) and, during experiment II, one more stand was presented to the ants during testing (Figure 3) (see also below 'Experimental planning').

During training, one stand for experiments I and II, and two stands for experiment III were deposited near the ants' food (Figure 2, 4, 6, lower part). During experiments I and II, the stand bore a given number of blue circles, one of these circles being obliquely crossed by a black segment $(0.6 \times 0.15 \mathrm{~cm})$ (this showing the circle expected to be subtracted). During experiment III, one stand bore a given number of blue circles, the other stand bore the same number of circles but they were empty except the one to subtract which was filled in blue and crossed by an oblique black segment. During experiments I and II, the numbers of blue circles equaled 5, 4, 3, 2 for colonies A and $\mathrm{B}, \mathrm{C}$ and $\mathrm{D}, \mathrm{E}$ and $\mathrm{F}$, as well as $\mathrm{G}$ and $\mathrm{H}$ respectively, with the $5^{\text {th }}$, the $4^{\text {th }}$, the $3^{\text {rd }}$, the $2^{\text {nd }}$ duly crossed respectively (Figures 8, 9, left part). During experiment III, the numbers of blues circles borne by one stand equaled 3, 2, 5, 4 for colonies $\mathrm{A}$ and $\mathrm{B}, \mathrm{C}$ and $\mathrm{D}, \mathrm{E}$ and $\mathrm{F}$, as well as $\mathrm{G}$ and $\mathrm{H}$ respectively, and the numbers of circles borne by the second stand equaled also 3, 2, 5, 4 for colonies $\mathrm{A}$ and $\mathrm{B}, \mathrm{C}$ and $\mathrm{D}, \mathrm{E}$ and $\mathrm{F}$, as well as $\mathrm{G}$ and $\mathrm{H}$ respectively, 2, 1, 4, 3 being empty, the $3^{\text {rd }}$, the $2^{\text {nd }}$, the $5^{\text {th }}$, the $4^{\text {th }}$ being filled in blue and crossed by a black segment respectively (Figure 10, left part).

During testing, two stands were presented to the ants for experiments I and III, and three stands were presented to the ants for experiment II (Figure 2, 4, 6, upper part; see also below 'Testing the ants'). One stand bore the same number of blue circles than that used during training but without the crossed circle (= defined as the expected correct subtracted number), the other stand bore the same number of blue circles than that used during training including the crossed circle which was this time not crossed (= defined as the expected incorrect result, the subtraction having not been made), and for experiment II only, the third stand bore the crossed circle presented during training and located at its original place (Figure $8,9,10$, right part). 


\subsection{Experimental Planning}

This planning is schematically presented in Figure 7. Experiments I, II and III were made of four parts, each part conducted on two colonies. The subtractions 5-1, 4-1, 3-1, 2-1 were examined on colonies A and B, C and D, E and $\mathrm{F}$, as well as $\mathrm{G}$ and $\mathrm{H}$ during experiment I and II, while the subtractions 3-1, 2-1, 5-1, 4-1 were examined on colonies $\mathrm{A}$ and $\mathrm{B}, \mathrm{C}$ and $\mathrm{D}, \mathrm{E}$ and $\mathrm{F}$, as well as $\mathrm{G}$ and $\mathrm{H}$ during experiment III.

For each experiment, the first part started at day 1 , the second part at day 2 , the third at day 3 , and the fourth at day 4. Training the ants lasted two days for experiments I and III, and only one day for experiment II since it was identical to that of experiment I and was thus a second conditioning. Consequently, for experiments I and III, training occurred during days 1 and 2 for colonies $\mathrm{A}$ and $\mathrm{B}$, during days 2 and 3 for colonies $\mathrm{C}$ and $\mathrm{D}$, during days 3 and 4 for colonies $\mathrm{E}$ and $\mathrm{F}$, during days 4 and 5 for colonies $\mathrm{G}$ and $\mathrm{H}$, the testing sessions occurring thus at days $3,4,5$ and 6 for colonies $\mathrm{A}$ and $\mathrm{B}, \mathrm{C}$ and $\mathrm{D}, \mathrm{E}$ and $\mathrm{F}$, as well as $\mathrm{G}$ and $\mathrm{H}$ respectively. For experiment II, training occurred during day 1 for colonies $\mathrm{A}$ and $\mathrm{B}$, during day 2 for colonies $\mathrm{C}$ and $\mathrm{D}$, during day 3 for colonies $\mathrm{E}$ and $\mathrm{F}$, during day 4 for colonies $\mathrm{G}$ and $\mathrm{H}$, the testing sessions occurring thus at days 2, 3, 4 and 5 for colonies $\mathrm{A}$ and $\mathrm{B}, \mathrm{C}$ and $\mathrm{D}, \mathrm{E}$ and F, as well as $\mathrm{G}$ and $\mathrm{H}$ respectively. One day elapsed between experiments I and II, and two days elapsed between experiments II and III (Figure 7).

\subsection{Experimental Design and Protocol}

\subsubsection{Training the Ants}

A stand (for experiment I and II) or two stands (for experiment III) were deposited near the ants' food, the face with the blue circles turned towards the nest entrance (Figures 2, 4, 6; Figures 8, 9, 10, left part). This lasted two or one days. At each of these training days, the ants of each colony surrounding the presented stands were counted six times over the day, and the two mean values were established (Tables 1,2,3, third column). The overall mean was then established and is given in the text. No statistical analysis was made on these numerical results.

\subsubsection{Testing the Ants}

After training, the ants of each colony were tested in a separate tray $(30 \mathrm{~cm} \times 15 \mathrm{~cm} \times 4 \mathrm{~cm})$ the borders of which having been slightly covered with talc to prevent escaping, and into which the two or three stands devoted to testing had been set (Figures 1, 3, 5, lower part; Figures 2, 4, 6, upper part; Figures 8, 9, 10, right part). Half of the tests were made with the correct result presented on the left, half of the tests were made with this correct result presented on the right. During experiment II, the stand with the crossed circle was also randomly set on the left or on the right of the tray. To make a test on a colony, 25 ants of that colony were transferred into their tray devoted to testing, and the ants present at a distance of $0-2 \mathrm{~cm}$ from each stand were counted 20 times over 10 experimental minutes. The means of these counts were established (Tables 1, 2, 3, fourth column). The proportion of correct responses (= the proportion of ants choosing the correct subtracted number of circles) was calculated and is given in the text.

For each test, the 20 numbers of counted ants were chronologically arranged and added by four, and the five sums obtained for each stand (these numbers are given in the text only) were compared to one another using the non-parametric test of Wilcoxon (Siegel \& Castellan, 1989).

\section{Results}

\subsection{Experiment I}

Numerical results are given in Table 1; some photos are shown in Figure 8.

During training, enough ants of colonies A and B were moving at any time near the presented stand bearing 5 circles including a crossed one. Meanly, 8.3 ants were counted there. During testing, these ants went preferentially towards the stand bearing 4 circles and far less towards that bearing 5 uncrossed circles. In total, 160 ants, i.e. $83.3 \%$, were seen in front of the stand with 4 circles and 32 ants, i.e. $16.7 \%$, were seen in front of the stand with 5 circles. Summed by four over the experimental time, the numbers of ants counted near 4 circles equaled 28, 33, 30, 32,37 , and those of ants counted near 5 circles equaled $4,8,5,5,10$. These two series of numbers statistically differed $(\mathrm{N}=5, \mathrm{~T}=15, \mathrm{P}=0.031)$. The ants chose thus the number of circles seen during training minus the crossed one, i.e. what resembled the most to what they saw during training.

During their training to 4 circles one of which being crossed, several ants of colonies C and D were at any time moving in the vicinity of this cue. They were meanly 10.8 in doing so, what was enough for allowing them seeing and memorizing the presented cue. When tested, the ants of the two colonies essentially went to the stand bearing 3 circles. In total, 105 ants, i.e. $85.4 \%$ were counted in front of 3 circles and 18 ones, i.e. $14.6 \%$ in front of 4 circles. Summed by four over the experimental time, the numbers of ants seen near 3 circles equaled 16, 18, 20, 28, 23, and 
those of ants seen near 4 circles equaled $2,3,5,4,4$. These two series of numbers statistically differed $(\mathrm{N}=5, \mathrm{~T}=$ $15, \mathrm{P}=0.031$ ). The ants chose thus the number of circles seen during training excluding the crossed one, what corresponded the best to what they saw during training, and thus, to the expected subtraction. Note that the present result (85.4\%) was slightly higher than the previous one (83.3\%).

While having near their food 3 circles of which one was crossed, the ants of colonies $E$ and $F$ were rather numerous at any time in the vicinity of this cue. Meanly 10.7 ants were counted there, what allowed them seeing and memorizing the presented cue. When tested after two training days, these ants of the two colonies went mostly to the stand bearing 2 circles and far less to the other stand. In total, 97 ants, i.e. $89 \%$, were counted in front of 2 circles and 12 ants, i.e. $11 \%$, were counted in front of 3 circles. Summed by four over the experimental time, the numbers of ants seen near 2 circles equaled 22, 15, 18, 21, 21, and those of ants seen near 3 circles equaled 2, 1, 2, 3,4 . These two series of numbers statistically differed $(\mathrm{N}=5, \mathrm{~T}=15, \mathrm{P}=0.031)$, the ants having thus essentially reacted to the number of circles seen during training minus the crossed one $(3-1)$. They did so with a score of $89 \%$, i.e. a higher score than those reached during the two first parts of the experiment (see above).

During their training to 2 circles one of which being crossed, many ants of colonies $\mathrm{G}$ and $\mathrm{H}$ moved at any time all around such a cue. They were meanly 8.3 in doing so, what was enough for allowing them seeing and memorizing the presented cue. Tested after two training days, these ants of colonies $\mathrm{G}$ and $\mathrm{H}$ responded preferentially to 1 circle. Only few ants went to the stand bearing 2 circles. In total, 149 ants, i.e. $92.5 \%$, were seen near 1 circle and 12 ants, i.e. $7.5 \%$, were seen near 2 circles. Summed by four over the experimental time, the numbers of ants counted in front of 1 circle equaled 31,37,27,29,25, and those of ants counted in front of 2 circles equaled 2, 3, 3, 2 , 2. These two series of numbers statistically differed $(\mathrm{N}=5, \mathrm{~T}=15, \mathrm{P}=0.031)$. The ants reacted thus mostly to the number of circles seen during training excluding the crossed circle (2-1), what looked the best similar to what they saw during training and corresponded thus to the expected subtraction. They did so with a score of $92.5 \%$, a slightly higher score than those reached during the three previous parts of the experiment.

The proportions of correct responses were $83.3 \%, 85.4 \%, 89.0 \%$ and $92.5 \%$ for the subtractions $5-1,4-1,3-1$ and 2-1 respectively. Consequently, it was easier for the ants to 'ignore' the crossed circle when the total number of circles was small and more difficult when this total was large.
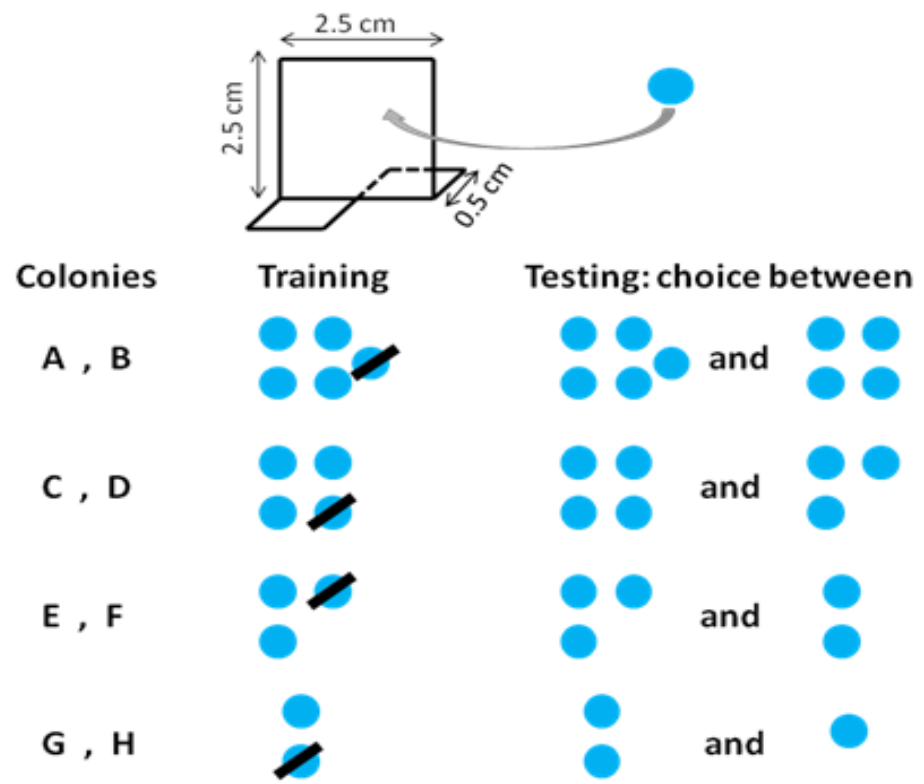

Figure 1. Schema of the cues used during experiment I

The ants were trained to a number of blue circles one of them being crossed by a black segment. They were then tested in front of the total number of uncrossed and crossed circles, and at the same time, in front of the number of uncrossed circles. Numerical results are given in Table 1; some photos of the experiment are shown in Figure 8. 
Table 1. Results of experiment I during which the ants were trained to a number of blue circles one of which being crossed by a black segment, and then tested in front of the number of uncrossed circles (the 'correct' $n^{\circ}$ ) and the total number of uncrossed and crossed circles (the 'wrong' $n^{\circ}$ )

\begin{tabular}{lcccc}
\hline \multirow{2}{*}{ Colonies } & \multirow{2}{*}{ Expected subtraction } & \multirow{2}{*}{ Training: mean numbers of ants near the cue } & \multicolumn{2}{c}{ Testing: mean numbers of ants reacting to } \\
\cline { 4 - 5 } & & & the 'correct' $\mathrm{n}^{\circ}$ of circles & the 'wrong' $\mathrm{n}^{\circ}$ of circles \\
\hline $\mathrm{A}$ and B & $5-1$ & 7.3 and 9.3 & 3.8 and $4.3=83.3 \%$ & 0.9 and 0.8 \\
$\mathrm{C}$ and D & $4-1$ & 10.4 and 11.1 & 2.2 and $3.1=85.4 \%$ & 0.4 and 0.6 \\
E and F & $3-1$ & 9.4 and 11.9 & 2.2 and $2.7=89.0 \%$ & 0.2 and 0.5 \\
G and H & $2-1$ & 9.0 and 7.5 & 4.2 and $3.3=92.5 \%$ & 0.4 and 0.3 \\
\hline
\end{tabular}

The ants of the eight used colonies reacted essentially to the numbers of uncrossed blue circles seen during training. Their responding score slightly increased with the decrease of the number of presented circles. Details can be found in the text, a schema of the numbers of circles in Figure 1, the experimental design in Figure 2, and some photos of the experiment in Figure 8.

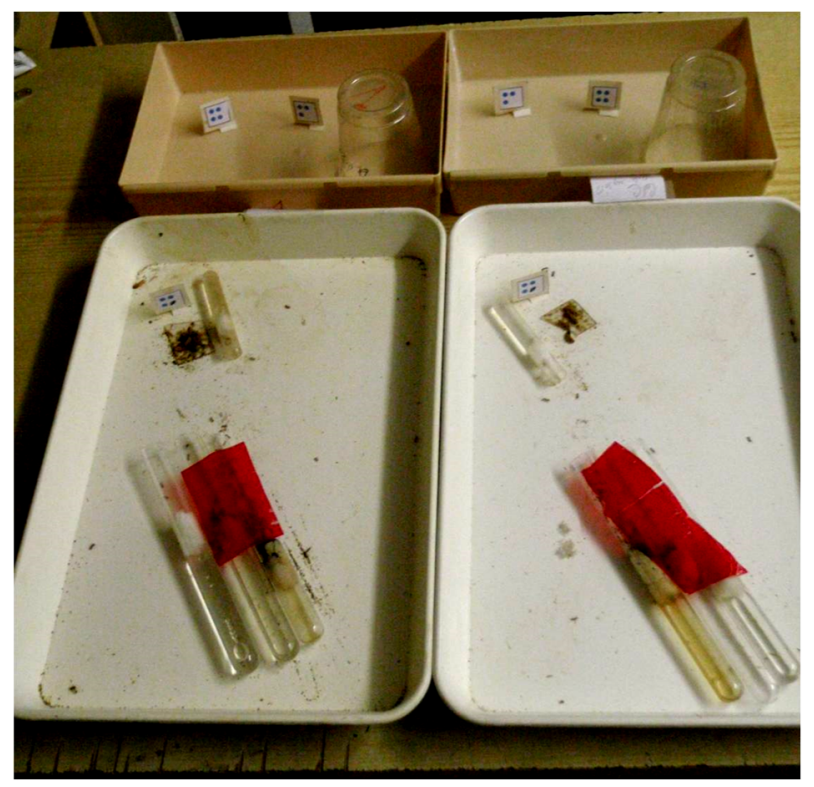

Figure 2. Experimental design of experiment I

A given number of blue circles, one of them being crossed by a black segment, was presented to the ants near their food (lower part of the figure), this being the ants' training. After two days, the ants were tested in separated trays (upper part of the figure) in front of the total number of uncrossed and crossed circles, and (at the same time) in front of the number of uncrossed circles, these two cues being set either on the left or on the right. The different numbers of blue circles used are schematized in Figure 1, results are given in Table 1, and views of the experiment are shown is Figure 8.

\subsection{Experiment II}

Numerical results are given in Table 2; some photos are shown in Figure 9.

During their training, the ants of colonies A and B were numerous enough all around the presented cue for seeing and memorizing it. Indeed, they were meanly 9.4 in doing so at any time. When tested one day later, the ants of colonies A and B behaved similarly: they went essentially to the stand bearing 4 blue circles. In total, 129 ants, i.e. $78.2 \%$, were counted near 4 circles, 30 ants, i.e. $18.2 \%$, near 5 circles, and 6 ants, i.e. $3.6 \%$, near the crossed circle. Summed by four over the experimental time, the numbers of ants seen in front of 4 circles equaled 27, 29, 29, 26, 18 , in front of 5 circles equaled $10,8,2,5,5$, and in front of the crossed circle equaled $1,1,1,0,3$. These three series of five numbers statistically differed $(\mathrm{N}=5, \mathrm{~T}=15, \mathrm{P}=0.031)$. The ants responded thus more to 4 circles than to 5 circles, just like during experiment I, and very weakly to the isolated crossed circle (a cue very different from what they saw near their food during training).

While being trained, the ants of colonies $\mathrm{C}$ and $\mathrm{D}$ were sufficiently numerous at any time in the vicinity of the presented cue for seeing and memorizing it. In fact, they were meanly 8.6 in doing so. After one day, the tested ants of the two colonies went mostly to the stand bearing 3 circles and far less to the other stands. In total, 143 ants, i.e. 
$76.1 \%$, were counted in front of 3 circles, 25 ants, i.e. $13.3 \%$, in front of 4 circles, and 20 ants, i.e. $10.6 \%$, in front of the crossed circle. Summed by four over the experimental time, the numbers of ants seen near 3 circles equaled 25,26 , $36,28,28$, those of ants seen near 4 circles equaled $8,5,4,5,3$, and those of ants seen near the crossed circle equaled $1,6,5,6,2$. These three series of five numbers statistically differed $(\mathrm{N}=5, \mathrm{~T}=15, \mathrm{P}=0.031)$. Consequently, as during experiment I, the ants reacted more to 3 circles than to 4 circles, and they here moreover slightly reacted to the alone crossed circle. It could be noted that the ants reacted less to the number of uncrossed plus crossed circles, but somewhat more to the isolate crossed circle than during the first part of the present experiment.

During their training, the ants of colonies $\mathrm{E}$ and $\mathrm{F}$ were numerous in moving all around the presented cues. They were meanly 10.9 in doing so, at any time, what was sufficient for allowing them to see and memorize the presented cue. After one training day, the ants of the two colonies similarly went preferentially to the stand bearing 2 circles. They went also, at a lower extent, to the stand bearing the crossed circle. In total, 117 ants, i.e. $75.5 \%$, were seen in front of 2 circles, 11 ants, i.e. $7.1 \%$, were seen in front of 3 circles, and 27 ants, i.e. $17.4 \%$, were seen in front of the crossed circle. Summed by four over the experimental time, the numbers of ants counted near 2 circles equaled 28, 21, 23, 25, 20 , those near 3 circles equaled 2, 3, 3, 3, 0, and those near the crossed circle equaled 9, 1,7,7,3. These three series of five numbers statistically differed $(\mathrm{N}=5, \mathrm{~T}=15, \mathrm{P}=0.01)$. The ants thus mostly responded to 2 circles, far less to 3 circles, and somewhat to the crossed circle. Note that the ants' response to the number of circles including the crossed one was lower than that given during the previous part of this experiment, and that the ants' response to the crossed circle was on the contrary higher than that presented during this previous part of the experiment.

When being trained, the ants of colonies $\mathrm{G}$ and $\mathrm{H}$ foraged sufficiently in the vicinity of the presented cue for seeing and memorizing it. They were indeed meanly 8.8 in doing so at any time. When tested after one day, the ants of the two colonies behaved similarly, moving essentially to the stand bearing 1 circle, somewhat to the stand bearing the crossed circle, and very weakly to the stand bearing 2 circles. In fact, in total, 78 ants, i.e. $70.3 \%$, were counted in front of 1 circle, 5 ants, i.e. $4.5 \%$, were counted in front of 2 circles, and 28 ants, i.e. $25.2 \%$, were counted in front of the crossed circle. Summed by four over the experimental time, the numbers of ants seen near 1 circle equaled $17,12,17,14,18$, seen near 2 circles equaled $0,0,2,0,3$, and seen near the crossed circle equaled 8, 5, 5, 3, 7 . These three series of five numbers statistically differed $(\mathrm{N}=5, \mathrm{~T}=15, \mathrm{P}=0.031)$. Consequently, the ants essentially reacted to 1 circle, somewhat to the crossed circle, and far less to 2 circles. Note that, once more, the ants' response to the number including the crossed circle was lower than that observed during the previous part of the experiment, and that their response to the crossed circle was higher.

Comparing the four parts of this experiment is interesting. Indeed, in the course of these four parts, the ants' response to the number of circles excluding the crossed one improved compared to their response to the number of circles including the crossed circle. Taking account of only these two responses and not of that to the crossed circle, the score of the ants' response to the number of uncrossed circles successively equaled $81.1 \%, 85.1 \%, 91.4 \%$ and $94 \%$. Similar proportions were also observed during experiment I (see above). Moreover, during experiment II, the ants' response to the crossed circle alone increased over the four parts of the experiment. Indeed, taking account of the ants' responses to all the elements presented, the score of their response to the crossed circle successively equaled $3.6 \%, 10.6 \%, 17.4 \%$, and $25.2 \%$ (see also Table 2, column 'crossed circle'). This proved that the ants reacted to what they saw during training, i.e. the uncrossed circles and the crossed circle. The last-mentioned became more and more visible over the four parts of experiment II, over the decrease of the total number of circles.

Table 2. Results of experiment II during which the training was identical to that made for experiment I, but the testing used one more stand bearing only the crossed circle

\begin{tabular}{lccccc}
\hline Colonies & Expected subtraction & Training: mean $n^{\circ}$ of ants & \multicolumn{3}{c}{ Testing: mean $\mathrm{n}^{\circ}$ of ants reacting to the } \\
\cline { 3 - 6 } & & near the cue & 'correct' $\mathrm{n}^{\circ}$ of circles & 'wrong' $\mathrm{n}^{\circ}$ of circles & crossed circle \\
$\mathrm{A}$ and $\mathrm{B}$ & $5-1$ & 10.0 and 8.8 & 2.3 and $4.2=78.2 \%$ & 0.8 and 0.8 & 0.1 and 0.2 \\
$\mathrm{C}$ and D & $4-1$ & 8.7 and 8.5 & 3.5 and $3.7=76.1 \%$ & 0.8 and 0.5 & 0.7 and 0.3 \\
$\mathrm{E}$ and F & $3-1$ & 9.3 and 12.5 & 3.2 and $2.7=75.5 \%$ & 0.5 and 0.1 & 0.8 and 0.6 \\
$\mathrm{G}$ and H & $2-1$ & 10.2 and 7.4 & 1.9 and $2.1=70.3 \%$ & 0.1 and 0.2 & 0.6 and 0.9 \\
\hline
\end{tabular}

The ants reacted essentially to the number of circles excluding the crossed one. They far less reacted to the number of circles including the crossed one and did so less and less when the number of circles became lower. All this was in agreement with results of experiment I. The ants also reacted to the crossed circle presented alone, and did so more and more when the total number of circles became lower. In fact, they reacted to what they saw the best during training. See details in the text, a schema of the numbers of circles in Figure 3, the experimental design in Figure 4, and some photos of the experiment in Figure 9. 

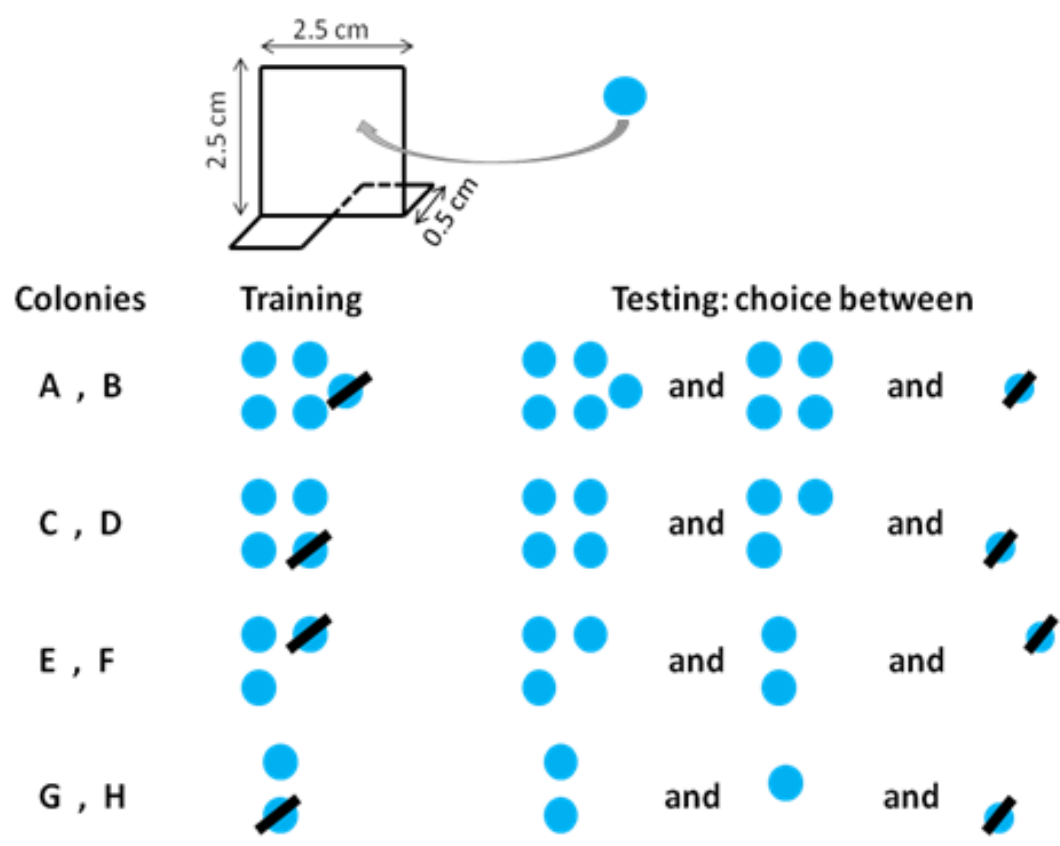

Figure 3. Schema of the cues used during experiment II

The cues used to train the ants were identical to those used for experiment I. Those used to test the ants were those used for experiment I with in addition, presented at the same time, the crossed circle alone. In other words, the ants were tested in front of the number of uncrossed and crossed circles, the number of uncrossed circles, and the crossed circle alone, these cues being indifferently set on the right, the middle or the left in the tray. Numerical results are given in Table 2 and some photos of the experiment in Figure 9.

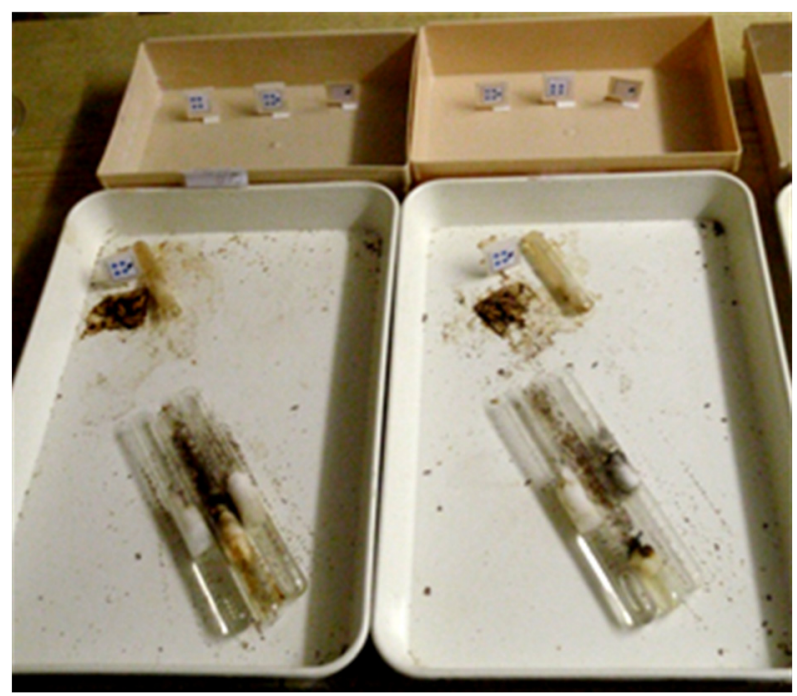

Figure 4. Experimental design of experiment II

A number of blue circles, one of them being crossed by a black segment, was presented to the ants near their food (lower part of the figure), this being the ants' training. After two days, the ants were tested in separated trays (upper part of the figure) in front of the number of uncrossed and crossed circles, the number of uncrossed circles, and the crossed circle alone, these three cues being indifferently set on the left, on the right or in the middle of the tray. The numbers of circles used, the results and some photos of the experiment can be found in Figure 3, in the text, and in Figure 9 respectively. 


\subsection{Experiment III}

Numerical results (arranged according to the numbers of blue circles used) are given in Table 3; some photos (arranged in the order of the used colonies) are shown in Figure 10.

While being trained to 3 blue circles and to 2 empty ones plus a blue crossed one, the ants of colonies A and B were numerous enough at any time all around these two cues for seeing and remembering them. Indeed, 8.8 ants were meanly counted in the vicinity of the two cues. Tested after two training days, the ants of the two colonies went preferentially towards the stand bearing 3 blue circles. In total, 185 ants, i.e. $81.1 \%$, were counted in front of the 3 blue circles while 43 ants, i.e. $18.9 \%$ were counted in front of 2 circles. Summed by four over the experimental time, the numbers of ants seen near 3 blue circles equaled 47, 44, 36, 35, 23, and those of ants seen near 2 blue circles equaled $17,5,5,10,6$. These two series of numbers statistically differed $(\mathrm{N}=5, \mathrm{~T}=15, \mathrm{P}=0.031)$. The ants have thus perceived, among 3 and 2 blue circles, 3 circles as being the picture set aside their food, and did not make any subtraction.

During their training, many ants of colonies $\mathrm{C}$ and $\mathrm{D}$ were seen at any time all around the two presented stands. Meanly 8.4 ants were counted on this area, the ants having thus been able to sufficiently see the presented numbers of circles and the proposed subtraction. After two training days, these ants moved preferentially towards the stand bearing 2 circles. In total, 171 ants, i.e. $83.8 \%$ were counted near 2 circles and 33 ants, i.e. $16.2 \%$, were counted near 1 circle. Summed by four over the experimental time, the numbers of ants seen in front of 2 circles equaled 27 , $32,39,39,34$, and those of ants seen in front of 1 circle equaled 9, 7, 4, 6, 7. These two series of numbers statistically differed $(\mathrm{N}=5, \mathrm{~T}=15, \mathrm{P}=0.031)$. The ants thus reacted mostly to 2 circles (what they saw during training) and far less to that number of circles minus the crossed circle presented on a separate stand during training.

During training, ants of colonies $\mathrm{E}$ and $\mathrm{F}$ were rather numerous, at any time, in the vicinity of the two stands deposited side by side near their food. Meanly, 10 ants were counted at this location. After having been trained during two days, the ants of the two colonies went preferentially towards the stand bearing 5 blue circles and less to that bearing 4 circles. In total, 109 ants, i.e. $82 \%$, were seen near 5 circles and 24 ants, i.e. $18 \%$, were seen near 4 circles. Summed by four over the experimental time, the numbers of ants which approached 5 circles equaled 23, $21,21,23,21$, and those of ants which approached 4 circles equaled 5, 4, 5, 5, 5. These two series of numbers statistically differed $(\mathrm{N}=5, \mathrm{~T}=15, \mathrm{P}=0.031)$. The ants reacted thus essentially to the number of uncrossed blue circles seen near their food during training, and took nearly no account of the information 'a circle is crossed by a black segment' given on another stand.

While being trained, the ants of colonies $\mathrm{G}$ and $\mathrm{H}$ were numerous enough all around the two presented stands for seeing and memorizing the number of blue circles (on a stand) and the crossed circle to subtract (on an aside stand). They were meanly 7.5 in moving at any time in the vicinity of these cues. When tested after two training days, these ants approached essentially the stand bearing 4 circles. Meanly, they were 3.7 in doing so. In total, 146 ants, i.e. $83.9 \%$, were seen in front of 4 circles, and 28 ants, i.e. $16.1 \%$, were seen in front of 3 circles. Summed by four over the experimental time, the numbers of ants counted near 4 circles equaled 25, 26, 30, 37, 28, and those of ants counted near 3 circles equaled $4,5,4,7,8$. These two series of numbers statistically differed $(\mathrm{N}=5, \mathrm{~T}=15, \mathrm{P}=$ 0.031 ), the ants having thus mostly approached the stand with 4 circles (identical to that seen near their food during training) and having taken no account of the information 'one circle is crossed' given apart on another stand.

The results of the four parts of experiment III were in agreement with one another. Each time, the ants largely responded to the number of circles seen on a stand set near their food during training, and very weakly to that number minus the crossed circles shown on another stand during training (their response to that number minus 1 representing only $16 \%-18 \%$ of all their responses). They thus simply reacted to what was the most similar to what they saw during training. 


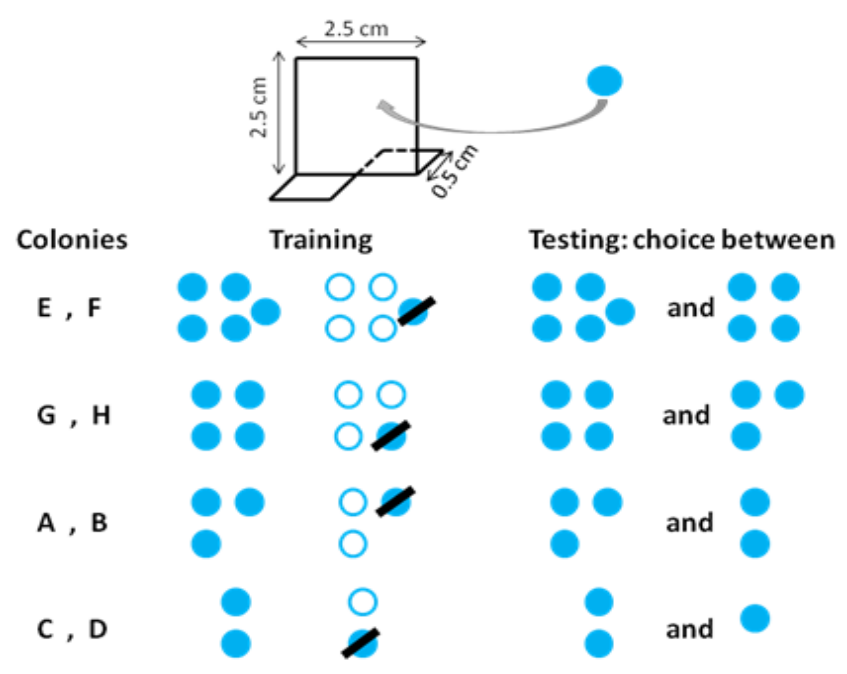

Figure 5. Schema of the cues used during experiment III

The ants were trained to a number of blue circles presented on a stand and, at the same time, presented on another stand set aside, to the same number of circles, one of them crossed by a black segment, the other ones being empty and equaling the complementary number of circles. They were then tested in front of the total number of uncrossed circles and of this number of blue circles minus the circle corresponding to the crossed one. Numerical results are given in Table 3, and some photos of the experiment in Figure 10.

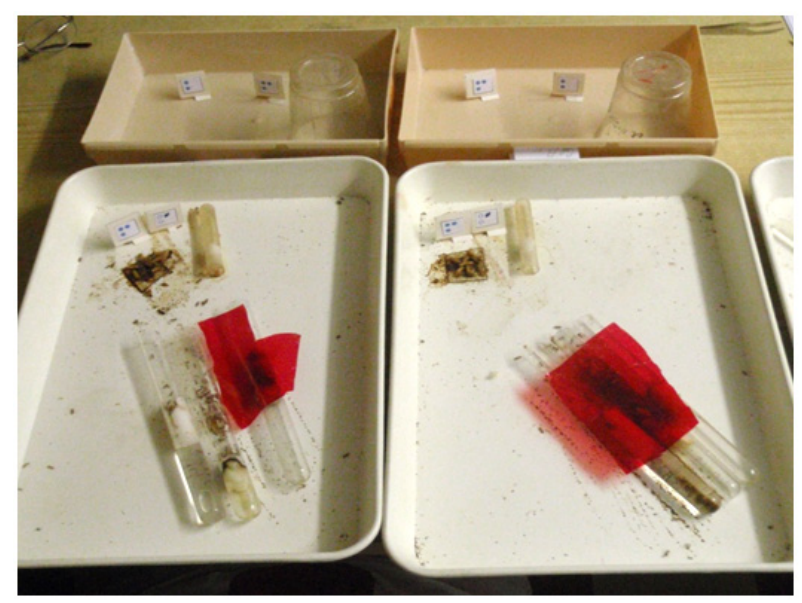

Figure 6. Experimental design of experiment III

During training (lower part of the figure), a number of blue circles was presented to the ants on one stand, and on another stand set aside, this number of circles, one being filled in blue and crossed by a black segment, the other ones being the complementary number of circles and being this time empty. The two stands were set near the ants' food. After two training days, the ants were tested in separated trays (upper part of the figure) in front of the total number of uncrossed colored circles presented during training, and of the same number of colored circles minus the crossed circle presented aside during training. These two cues were randomly set on the right or the left. The numbers of circles used are schematized in Figure 5. Results are given in Table 3 and views (arranged according to the used colonies) of the experiment are shown is Figure 10. 
Table 3. Results of experiment III during which ants were trained to a number of blue circles, as well as to the same number made of a crossed circle and the complementary number of empty circles

\begin{tabular}{lcccc}
\hline Colonies & Expected subtraction & Training: mean numbers of ants near the cues & $\begin{array}{c}\text { Testing: mean numbers of ants reacting to } \\
\text { the 'wrong' }{ }^{\circ} \text { of circles }\end{array}$ \\
\hline A and B & $3-1$ & 8.4 and 9.1 & 0.8 and $1.4=18.9 \%$ & 4.4 and 4.9 \\
C and D & $2-1$ & 7.8 and 9.0 & 0.4 and $1.3=16.2 \%$ & 3.5 and 5.1 \\
E and F & $5-1$ & 8.8 and 11.2 & 0.5 and $0.7=18.0 \%$ & 2.2 and 3.3 \\
G and H & $4-1$ & 8.0 and 7.0 & 0.5 and $0.9=16.1 \%$ & 2.6 and 4.7 \\
\hline
\end{tabular}

The ants of the eight colonies reacted essentially to the total number of blue circles seen during training taking no account of the crossed circle shown apart. Details, a schema of the numbers of circles, the experimental design, and some photos of the experiment can be found in the text, and in Figures 5, 6 and 10 respectively.

Experiment I
\begin{tabular}{|l|c|c|c|c|}
\hline Days & Colonies A, B & Colonies C, D & Colonies E, F & Colonies G, H \\
\hline 1 & trained to $5-1$ & trained to $4-1$ & & \\
2 & & trained to $3-1$ & trained to $2-1$ \\
3 & tested to 4 and 5 & tested to 3 and 4 & tested to 2 and 3 & tested to 1 and 2 \\
\hline & & & & \\
5 & & & & \\
6
\end{tabular}

\section{Experiment II}

\begin{tabular}{|l|c|c|c|c|}
\hline Days & Colonies A, B & Colonies C, D & Colonies E, F & Colonies G, H \\
\hline 1 & trained to 5-1 & trained to 4-1 & & \\
2 & tested to 4 and 5 & tested to 3 and 4 & $\begin{array}{c}\text { trained to 3-1 } \\
\text { tested to } 2 \text { and } 3\end{array}$ & $\begin{array}{c}\text { trained to 2-1 } \\
\text { tested to } 1 \text { and } 2\end{array}$ \\
\hline
\end{tabular}

\section{Experiment III}

\begin{tabular}{|l|c|c|c|c|}
\hline Days & Colonies A, B & Colonies C, D & Colonies E, F & Colonies G, H \\
\hline 1 & trained to 3-1 & trained to 2-1 & trained to 5-1 & trained to 4-1 \\
2 & tested to 2 and 3 & tested to 1 and 2 & tested to 4 and 5 & tested to 3 and 4 \\
4 & & & & \\
5 & & & & \\
6
\end{tabular}

Figure 7. Experimental planning

The cues used for the three experiments somewhat differed and are shown in Figures 1, 3 and 5. The corresponding experimental designs are shown in Figures 2, 4, 6, and some views of the experiments in Figures 8, 9, 10. Numerical results are in Tables 1, 2, 3. Views in Figures 8, 9 and results in Table 1, 2 are in the same order; views in Figure 10 and results in Table 3 are not; the lower part of the above Figure 7 helps understanding this difference. 
Training to $5-1$

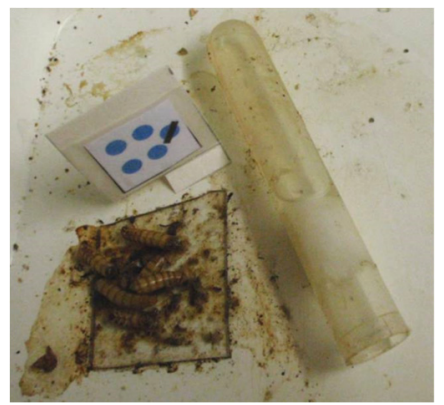

Training to 4 - 1

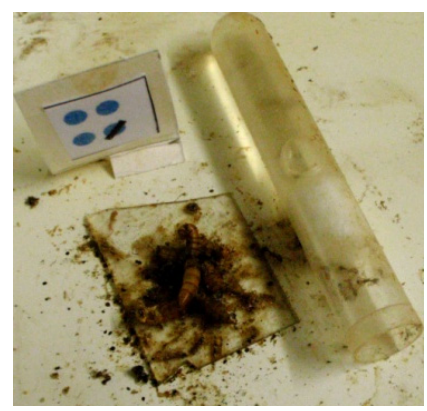

Training to 3 - 1

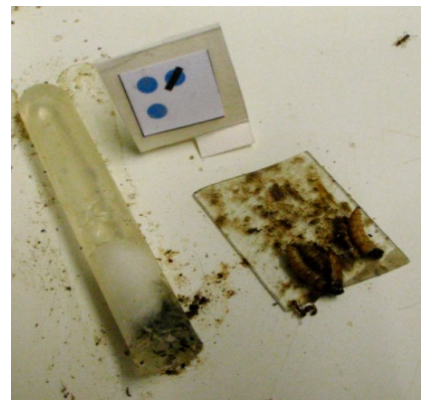

Training to 2 - 1

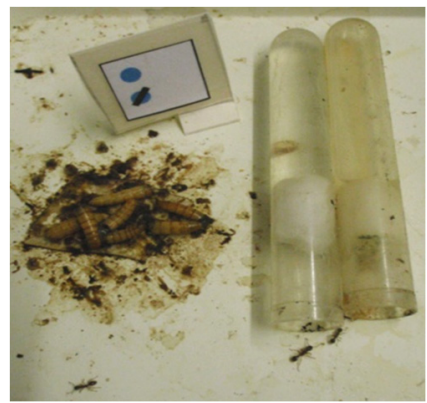

Testing
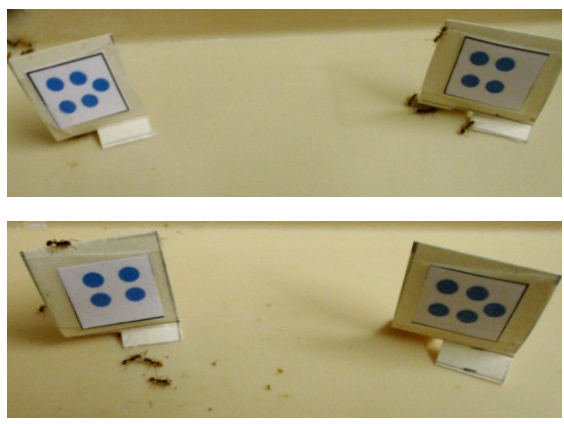

Testing

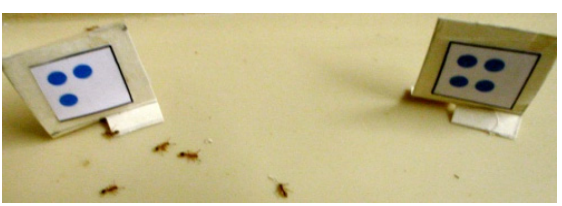

colony D

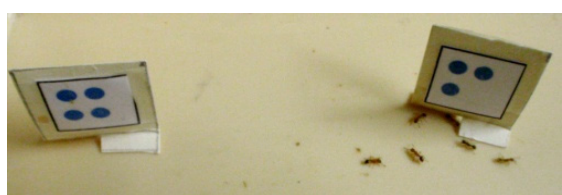

Testing
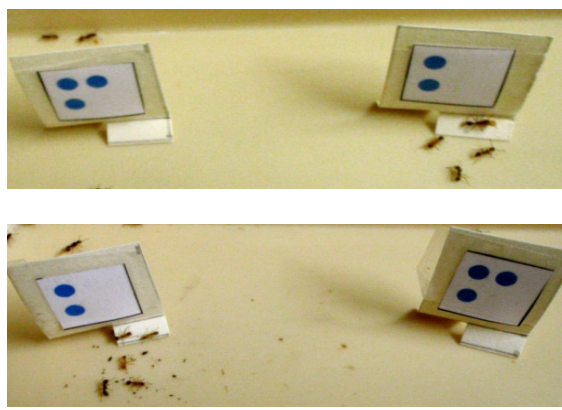

Testing

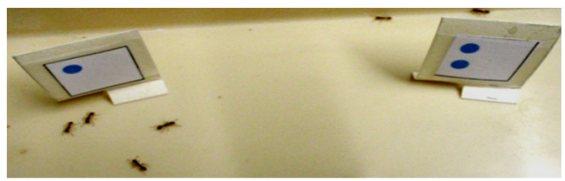

colony $\mathrm{H}$

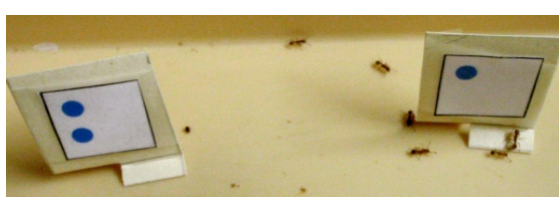

Figure 8. Some views of experiment I

The ants of colonies A and B, C and D, E and F, G and H were trained to 5, 4, 3, 2 blue circles respectively, one of which being crossed by a black segment (left part of the figure). They were then tested in front of the total number of circles, but all of them uncrossed, and of the number of uncrossed circles displayed during training (right part of the figure), these two cues being set on the right or the left. The ants reacted mostly to the number of uncrossed circles (i.e. the total number of circles minus the crossed one). Numerical results are given in Table 1, details and statistics in the text. The ants better reacted when the presented number of circles was lower. 
Training to 5 - 1

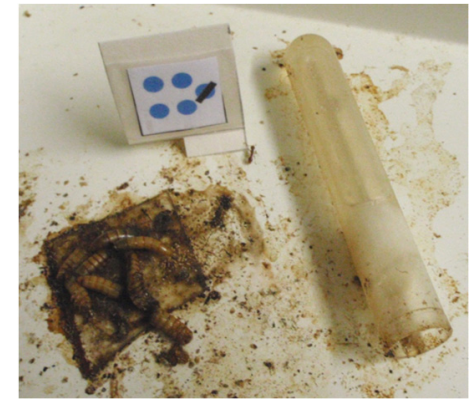

Training to 4 - 1

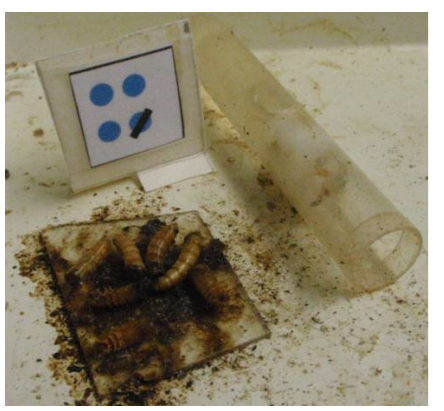

Training to 3 - 1

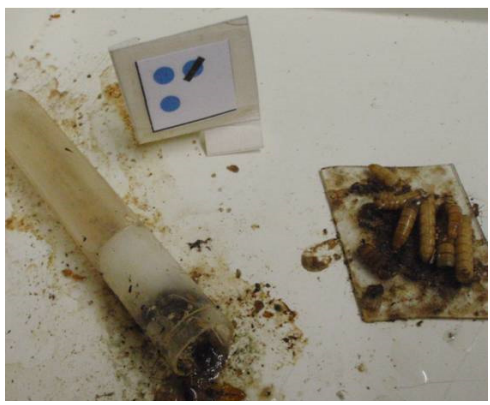

Training to 2 - 1

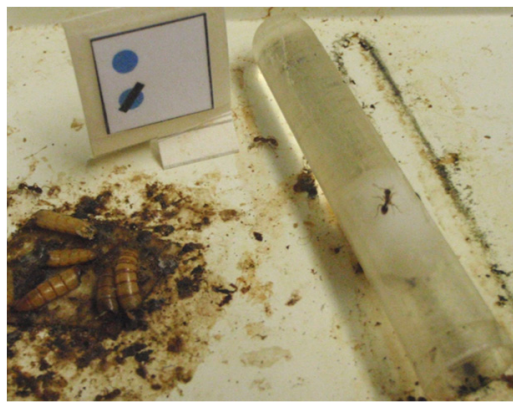

Testing
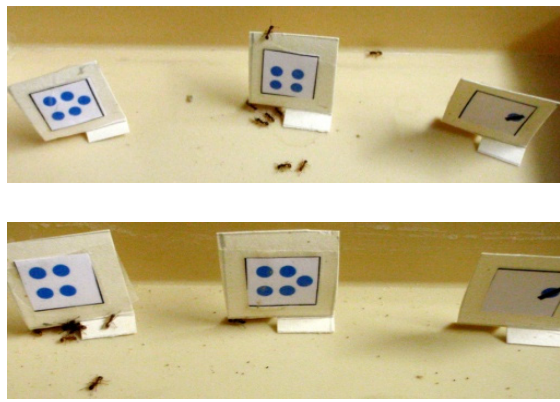

Testing

colony $\mathrm{C}$

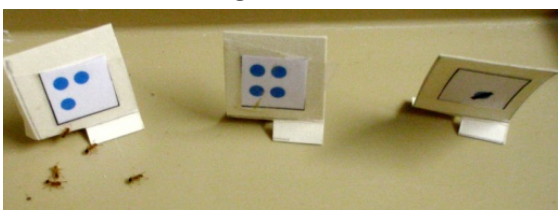

colony D

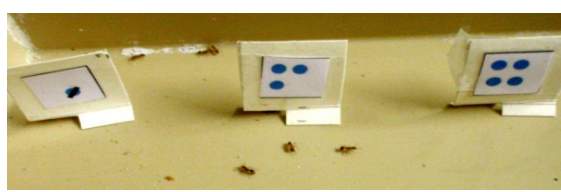

Testing

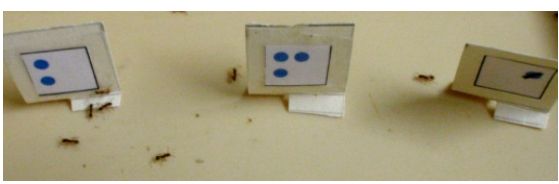

colony $\mathrm{F}$

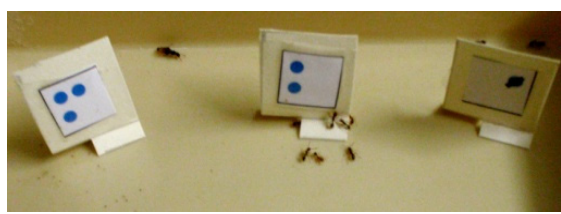

Testing

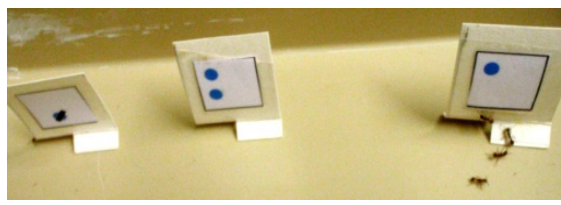

colony $\mathrm{H}$

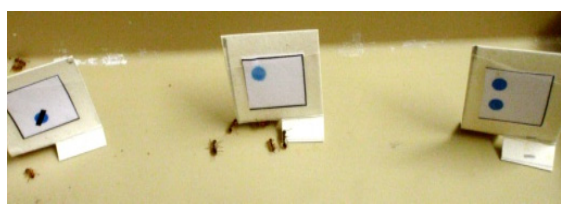

Figure 9. Some views of experiment II

The ants of colonies A and B, C and D, E and F, G and H were trained to 5, 4, 3, 2 blue circles respectively, one of which being crossed by a black segment (left part of the figure). They were then tested in front of the total number of uncrossed and crossed circles all being this time uncrossed, of the number of uncrossed circles, and of the crossed circle alone (right part of the figure), these three cues being indifferently set on the right, the left or in the middle of the tray. The ants reacted mostly to the numbers of uncrossed circles (the total number of circles minus the crossed one), just like in experiment I and did so better for fewer numbers of circles. They also slightly reacted to the crossed circle, the more when the number of circles was lower. Numerical results are given in Table 2, and details and statistics in the text. 
Training to $3 \mid 3-1$

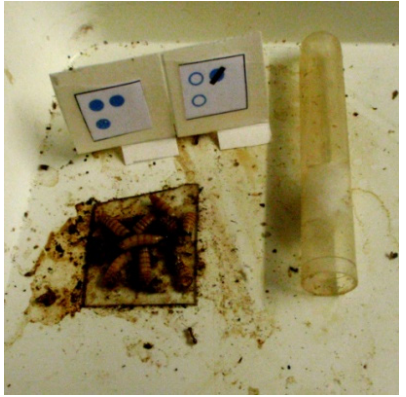

Training to $2 \mid 2-1$

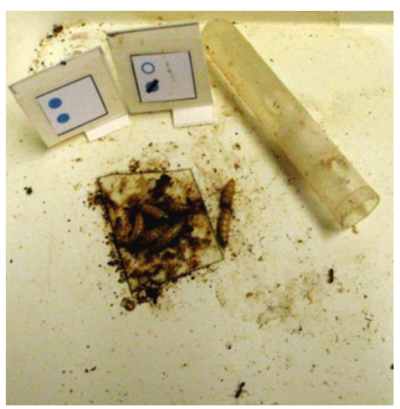

Training to $5 \mid 5-1$

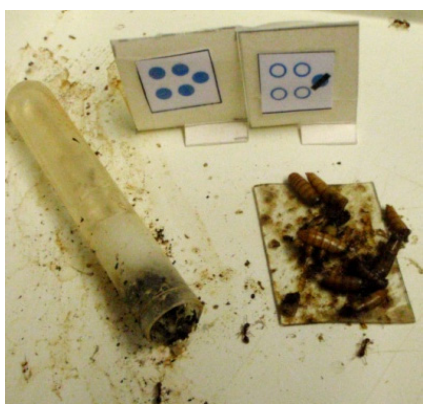

Training to $4 \mid 4-1$

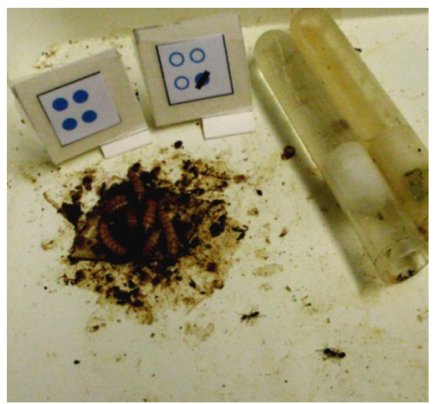

Testing

colony A

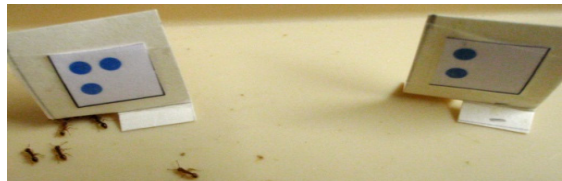

colony B

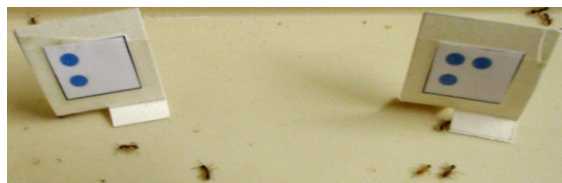

Testing

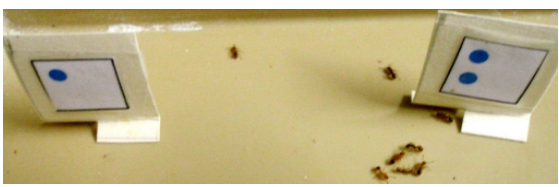

colony D

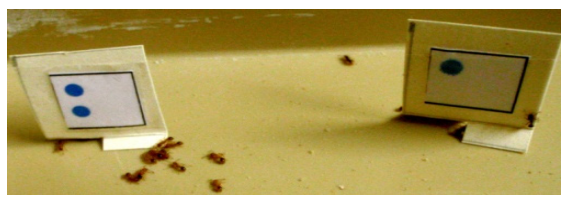

Testing
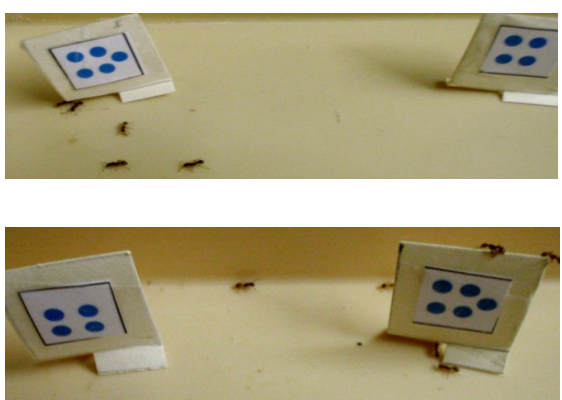

Testing

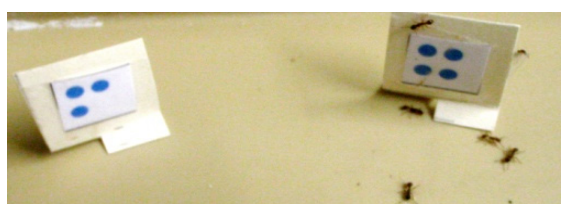

colony $\mathrm{H}$

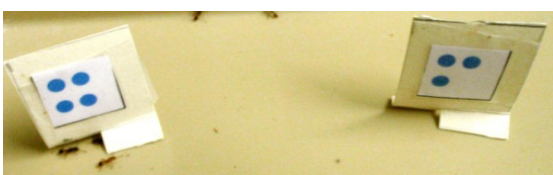

Figure 10. Some views of experiment III

The ants of colonies A and B, C and D, E and F, G and H respectively were trained to 3, 2, 5, 4 blue circles and, presented apart, to these numbers of circles one of which being filled in blue and crossed by a black segment, the other ones being the complementary number of circles which were this time empty (left part of the figure). They were then tested in front of the total number of uncrossed blue circles and of the same number of blue circles minus one (i.e. 2, 1, 4, 3) (right part of the figure), these two cues being set on the left or the right in the tray. The ants essentially reacted to the initial total number of blue circles. Numerical results (arranged according to the numbers of blue circles used) are given in Table 3, and details and statistics can be found in the text. 


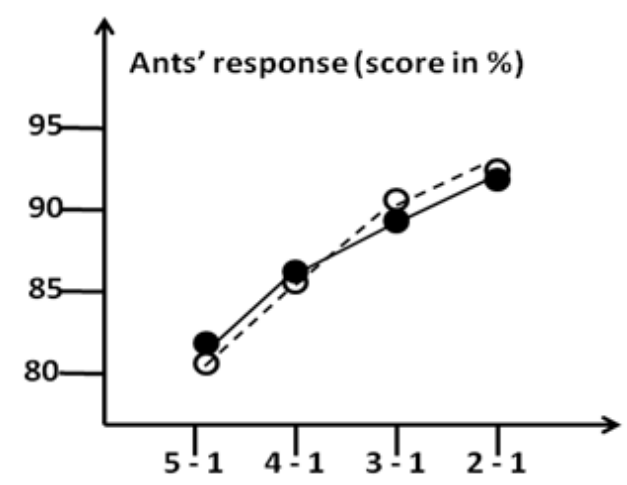

Figure 11. Ants' accuracy of response (y axis) to four subtractions (x axis)

The two curves show the scores of the ants' responses obtained during experiment I (black circles) and II (empty circles) to the numbers of uncrossed elements representing concretely the subtractions 5-1, 4-1, 3-1, and 2-1. These scores slightly increased when the number of elements became lower, or in other words, the score of correct responses decreased when the numbers of presented elements became larger.

\section{Discussion}

Here we have shown that the workers of the ant $M$. sabuleti could 'subtract' a crossed circle from a number of circles when trained to them set all together on the same stand, but failed in doing so when trained to a number of uncrossed elements and, set aside on a separate stand, to this number including a crossed one. The ants seemed thus to do a subtraction when the latter was concretely presented, and not when the result was not shown. Such findings are in agreement with those previously obtained about the adding capability: the ants could do what looked as an addition when seeing concretely at the same time the two numbers to be added, and could not do so when seeing consecutively the two numbers to be added (Cammaerts \& Cammaerts, 2010 c, d).

To complete our study of the ants' numerosity abilities, one more observation should be performed. Indeed, $M$. sabuleti uses essentially olfactory cues for navigating, and uses visual cues only in the absence of odor (Cammaerts \& Rachidi, 2009). The aim of a future work will thus be to examine if these ants' can add and subtract olfactory cues, what we intend to conduct in the way we here studied these ants' ability in adding and subtracting visual cues.

Ants exhibit also another counting, adding, and subtracting ability. Foragers of the red wood ant Formica polyctena can evaluate the walked distance by counting the number (the quantity) of steps travelled before reaching food. They also appear to be able to add or subtract numbers of walked steps and doing so, to shorten the time of transmission of the information to recruited congeners (Reznikova \& Ryabko, 2011). M. sabuleti workers can also evaluate the traveled distance through their number of walked steps, i.e by odometry (Cammaerts 2005). This trait has also been found in the desert ant Cataglyphis fortis (Wittlinger, Wehner \& Wolf, $2006,2007)$ and may be rather common in ants. This, along with the numerosity abilities described in the seven above cited works may help M. sabuleti workers to collect food, forage, and find their way to the nest.

To come back to the present work, during experiment II, we also showed that the ants somewhat responded to the crossed circle presented alone, and did so better when the number of circles was lower, i.e. when the crossed circle, each time set in a conspicuous location, was visually easier to perceive. The ants reacted thus, as a matter of fact, to what they saw during training. During experiments I and II, the ants better responded to the number of uncrossed circles when the number of circles was smaller. For the subtractions 5-1, 4-1, 3-1, and 2-1 examined in experiment I, the ants' scores equaled $83.3 \%, 85.4 \%, 89.0 \%$, and $92.5 \%$ respectively; for the same subtractions examined in experiment II, the ants' scores equaled $81.1 \%, 85.1 \%, 91.4 \%$ and $94.0 \%$ (Figure 11). The agreement between the results of experiments I and II is outstanding, and the relation between the ants' scores and the presented numbers of elements can be used in a future study on the ants' arrangement of amounts on a scale. It had also been observed that ants better added numbers of identical elements seen simultaneously when the number of elements was lower (Cammaerts \& Cammaerts, 2019c). These two corroborating observations can be explained by the way the ants evaluate a number of elements, and 'seem' to add or subtract a few of them: they appear to simply subitize numbers of elements, what is easier when the number is small and becomes difficult and rapidly impossible when the number increases. We thus used the words addition and subtraction by convenience, the ants only subitizing two numbers of elements seen at the same time (= the 'addition') and 
visually remembering the numbers of uncrossed elements (= the 'subtraction', i.e. what looks to be subtracting). Note that such a way of doing basic arithmetic is also that of 3-5 years old children who begin to learn the numbers as well as their addition and subtraction, through a concrete representation of these numbers and operations (Fuson, 1988). Later, 6-8 years old children learn to add and to subtract numbers first when no longer seeing concretely the operation to do but having the possibility to create this visualization, and finally without having such a possibility (Fuson, 1988). We have shown that the ants could not go beyond the initial concrete step of the numbers notion and the arithmetic operations. Young chicks might go a little beyond this initial step (Rugani et al., 2009). Moreover, in young children, arithmetic operations can be performed in the absence of a symbolic representation of the numbers (Barth, La Mont, Lipton, Dehaene, Kanursher, \& Spelke, 2006).

Mathematical thinking, its learning and its use are processed in a specific zone of the vertebrates' brain (Nieder, 2005). Such an advanced research on brain functioning may be done on ants and on bees, since brain functioning under stimulation by odors has already been examined in these insects (e.g. Sandoz, 2011; Lopez-Riquelme, Hermandez-Falcon \& Ramon, 2009).

\section{Conflict of interests}

The authors declare that there is no conflict of interests regarding the publication of this paper.

\section{References}

Agrillo, C., Dadda, M., Serena, G., \& Bisazza, A. (2008). Do fish count? Spontaneous discrimination of quantity in female mosquitofish. Animal Cognition, 11(3), 495-503.

Barth, H., La Mont, K., Lipton, J., Dehaene, S., Kanursher, N., \& Spelke, E. (2006). Non-symbolic arithmetic in adults and young children. Cognition, 98(3), 199-222.

Boysen, S. T., \& Berntson, G. G. (1989). Numerical competence in a chimpanzee (Pan troglodytes). Journal of comparative Psychology, 103(1), 23-31.

Brannon, E. M., Wusthoff, C. J., Gallistel, C. R., \& Gibbon, J. (2001). Numerical subtraction in the pigeon: evidence for a linear subjective scale. Psychological Sciences, 12, 238-243.

Cammaerts, M.-C. (2005). How do workers of the ant Myrmica sabuleti (Hymenoptera, Formicidae) estimate the distance they walk? Belgian Journal of Entomology, 7, 87-98.

Cammaerts, M.-C. (2008). Visual discrimination of cues differing as for their number of elements, their shape or their orientation, by the ant Myrmica sabuleti. Biologia, 63, 1169-1180.

Cammaerts, M.-C., \& Cammaerts, R. (2019a). Ants are at the first stage of the notion of zero. International Journal of Biology, 11(1), 54-65.

Cammaerts, M.-C., \& Cammaerts, R. (2019b). Ants fail to add numbers of same elements seen consecutively. International Journal of Biology, 11(3), 37-48.

Cammaerts, M.-C., \& Cammaerts, R. (2019c). Ants' capability of adding numbers of identical elements. International Journal of Biology, 11(3), 25-36.

Cammaerts, M.-C., \& Cammaerts, R. (2019d). Ants' notion of zero through the perception of the absence of an odor. International Journal of Biology, 11(2), 1-12.

Cammaerts, M.-C. \& Rachidi, Z. (2009). Olfactory conditioning and use of visual and odorous elements for movement in the ant Myrmica sabuleti (Hymenoptera, Formicidae). Myrmecological News, 12, 117-127. https://myrmecologicalnews.org/.../index.php?...117-127...

Cox, L., \& Montrose, T. (2016). Quantity discrimination in domestic rats, Rattus norvegicus. Animal (Basel), $6(8), 46$.

Fuson, K. C. (1988). Children's counting and concepts of number. New York: Springer-Verlag. Retrieved from https://www.springer.com/la/book/9781461283355

Howard, S. R., Avarguès-Weber, A., Garcia, J. E., Greentree, A. D., \& Dyer, A. G. (2019). Numerical cognition in honeybees enables addition and subtraction. Cognitive Neuroscience, 5, 1-6. Retrieved from $\mathrm{http}: / /$ advances.sciencemag.org/

Lopez-Riquelme, G. O., Hermandez-Falcon, J., \& Ramon, F. (2009). Correlations between antennae (electroantennogram) and brain (ERPs) response during odour stimulation in ants. Program N0 68.20/V4. Neuroscience Meeting Planner. Chicago, IL: Society for Neuroscience. Retrieved from https://www.researchgate.net/...Antennae_Electroantennogram...Br... 
Nieder, A. (2005). Counting on neurons: The neurobiology of numerical competence. Nature Reviews, Neuroscience, 6, 177-190.

Pepperberg, I. M. (2006). Grey parrot (Psittacus erithacus) numerical abilities: Addition and further experiments on a zero-like concept. Journal of Compartive Psychology, 120, 1-11.

Pepperberg, I. M. (2012). Further evidence for addition and numerical competence by a grey parrot (Psittacus erithacus). Animal Cognition, 15, 711-717.

Reznikova, Z. \& Ryabko, B. (2011). Numerical competence in animals, with an insight from ants. Behaviour, 148(4), 405-434. https://doi.org/10.1163/000579511X568562.

Rugani, R., Fontanari, L., Simoni, E., Regolin, L., \& Vallortigara, G. (2009). Arithmetic in newborn chicks. Proceedings of the Royal Society, B, 276, 2451-2460.

Sandoz, J. C. (2011). Behavioral and neurophysiological study of olfactory perception and learning in honeybees. Frontiers in Systems Neuroscience, 5, 98.

Siegel, S., \& Castellan, N. J. (1989). Nonparametric statistics for the behavioural sciences. Singapore, McGraw-Hill Book Company. Retrieved from https://www.amazon.com/Sidney-Siegel...Statistics.../B008 WDIR6

Sulkowski, G. M., \& Hauser, M. D. (2001). Can rhesus monkeys spontaneously subtract? Cognition, 79, 239-262.

Wittlinger, M., Wehner, R. \& Wolf, H. (2006). The ant odometer: stepping on stilts and stumps. Science, 312(5783), 1965-1967. https://doi.org/10.1126/science.1126912

Wittlinger, M., Wehner, R. \& Wolf, H. (2007). The desert ant odometer: a stride integrator that accounts for stride length and walking speed. Journal of Experimental Biology, 210, 198-207. https://doi.org/10.1242/jeb.02657

\section{Copyrights}

Copyright for this article is retained by the author(s), with first publication rights granted to the journal.

This is an open-access article distributed under the terms and conditions of the Creative Commons Attribution license (http://creativecommons.org/licenses/by/4.0/). 